\title{
Pressure Measurement Systems
}

Shown at right is the processor unit of System 8400 , an advanced system for measurement of gas and liquid pressure, along with a variety of other parameters, including voltage, frequency and digital inputs. At far right is an exploded view of the whole system. System 8400 offers exceptionally high speed data acquisition through parallel processing, and its modular design allows expansion from a relatively inexpensive entry level system by the addition of modular Input Units that can be installed or removed in minutes.

Typically used by aerospace firms for wind tunnel or flight test pressure measurement, or by industrial firms for scanning control loop pressures that govern plant processes, System 8400 is the latest advancement produced by Pressure Systems, Inc. (PSI), Hampton, Virginia, a thriving company whose business, and much of its product line, evolved from a single spinoff development.

PSI began life in 1977, its "plant" a single room in the home of founder and president Douglas B. Juanarena, its sole product an innovative pressure sensing device developed at Langley Research Center. Today, PSI manufactures 20 distinct products within four basic product lines and has annual sales of $\$ 8$ million, exports accounting for about 25 percent of it.

The PSI success story began in the early seventies when Langley Research Center was looking for a way to obtain better acccuracy and higher data rates in measuring airflow pressure at many points around a wind tunnel model. Mechanical systems then in use had a maximum capability of 10 measurements a second. To get the hundreds of measurements needed in a typical test, it was necessary to conduct many repetitive tunnel runs.

Additionally, inaccuracies were induced because test conditions changed over the lengthy period required to make the measurements. And there was the energy factor: energy costs were soaring in those crisis years and wind tunnels consume enormous amounts of energy. Langley embarked on an effort to get higher data

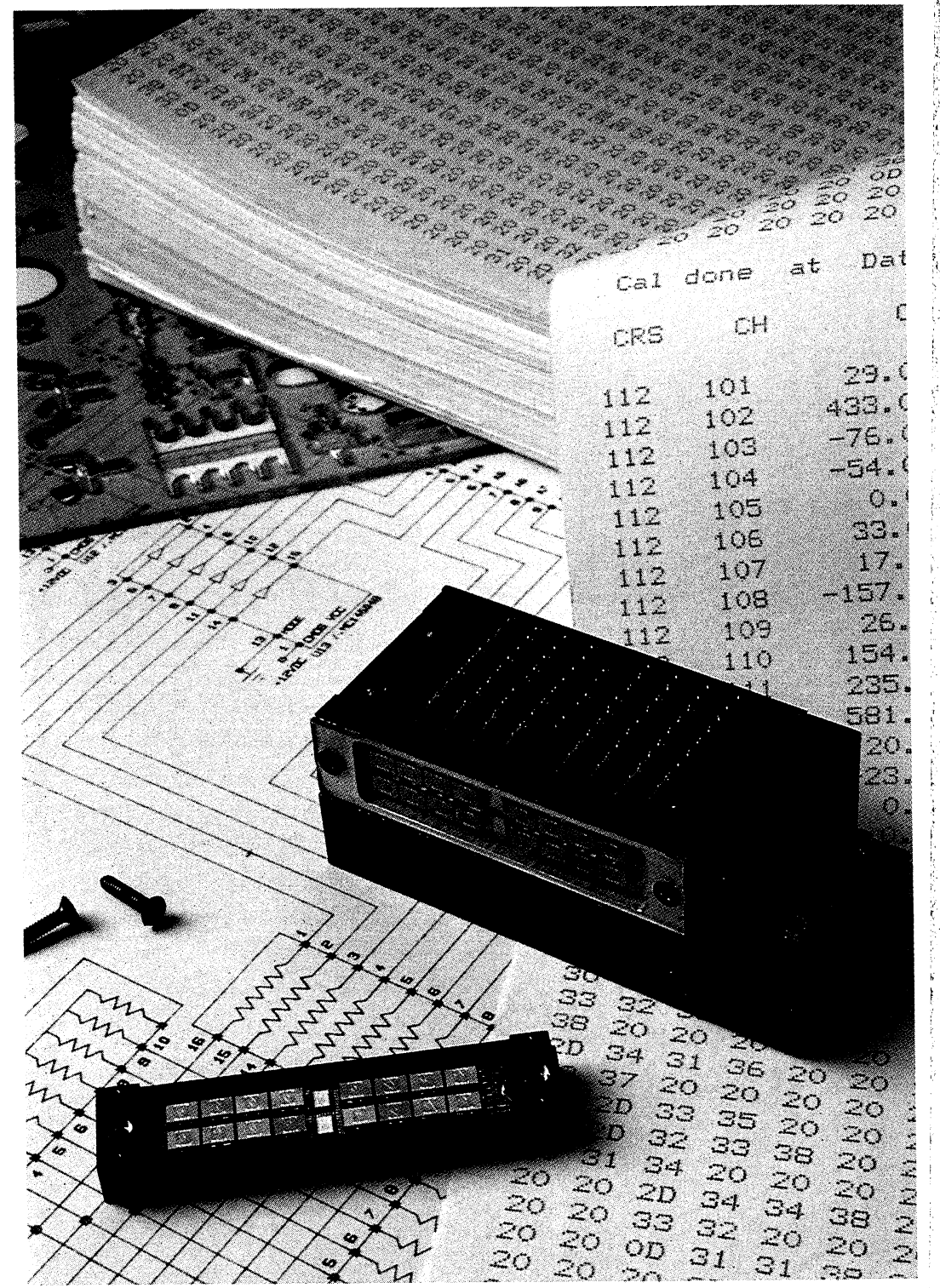



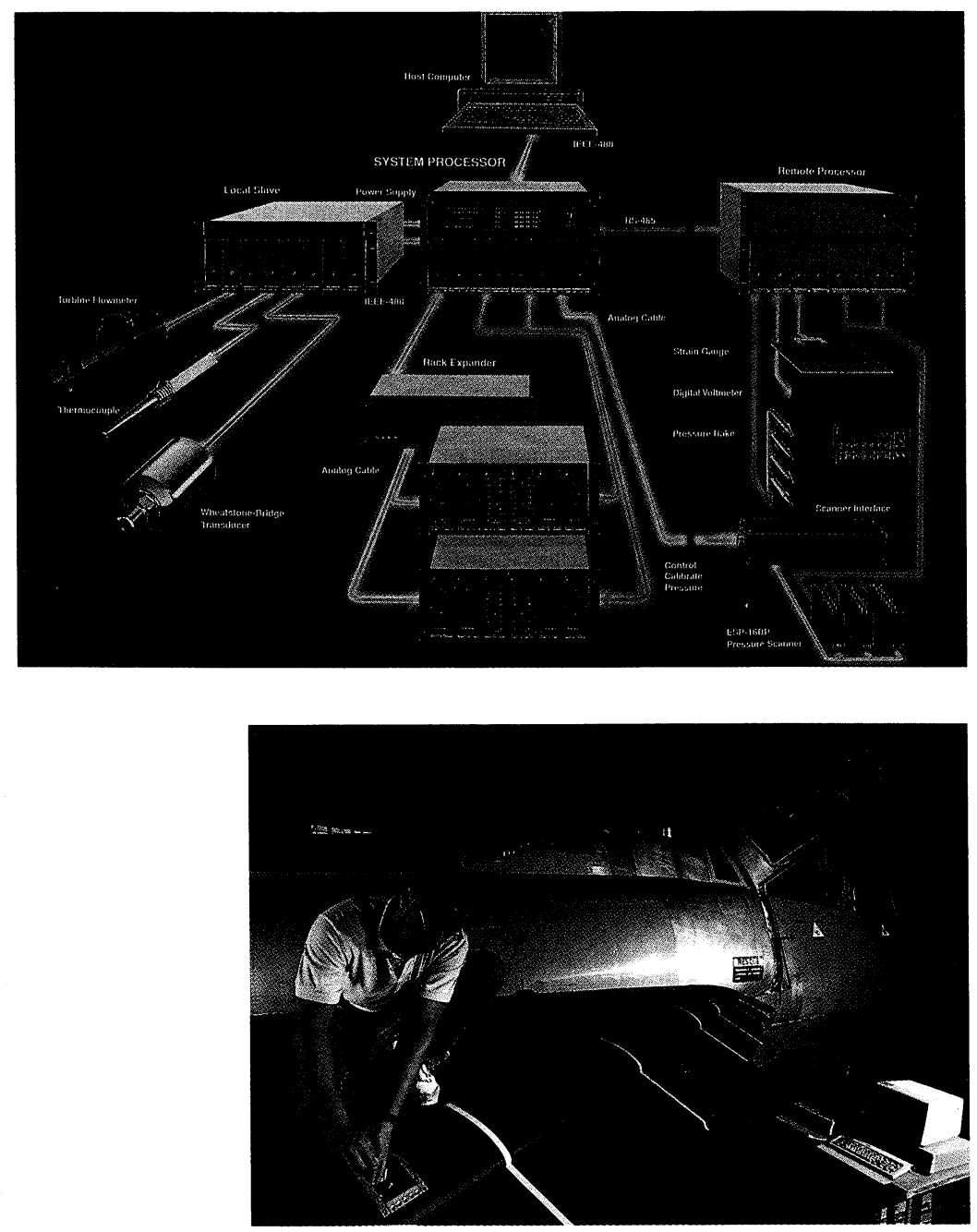

rates with greater accuracy while simultaneously shortening tunnel operating times.

The solution, developed by a team of engineers that included Douglas Juanarena, was a new technology known as ESP-electronically scanned pressure. The Langley ESP measurement system was based on miniature integrated circuit pressure-sensing transducers that communicated pressure information to a minicomputer. These sensors were capable of being calibrated while in use, an innovation that greatly increased accuracy. The high data rate was achieved by using one transducer for each pressure port in a wind tunnel, which would have been impractical with mechanical systems. The basic system, capable of making 10,000 measurements a second, was small, relatively low in cost and highly reliable.

In 1977, Juanarena formed PSI to exploit the NASA technology. In 1978 he left Langley, ob- tained a NASA license for the technology, and introduced the first commercial product, the 780B pressure measurement system, which quickly captured a large part of the pressure scanning market among U.S. government and industrial wind tunnels. Subsequently, the French and West German governments standardized on PSI instrumentation for their wind tunnels. PSI systems are also used for pressure measurements in flight; at left below an engineer is adjusting a wing-mounted unit that gathers data from a dozen sensors along the leading edge of the wing.

Looking to the broader potential of the technology in industrial applications, PSI developed a pressure scanner for automation of industrial processes where there is a need for making multiple pressure measurements quickly and with high accuracy. Now in its second design generation, the DPT-6400 is capable of making 2,000 measurements a second and has 64 channels that can be expanded to 256 channels by addition of slave units.

The new system 8400 , which can handle up to 400,000 measurements a second, represents PSI's bid to further exploit the $\$ 600$ million U.S. industrial pressure measurement market. The system is geared to provide a turnkey solution to physical measurement for both aerospace and general industrial applications. Its configuration is determined by the customer's need; a wide selection of Input Units allows the user to tailor the system to his own specific measurement and performance requirements.

PSI is still growing. In 1985, the company moved into a new 15,000 square foot plant, but outgrew it by 1989 , when an 8,800 square foot addition was constructed. PSI is now projecting additional plant expansion in 1992. Sales are expanding not only in the U.S. but abroad; in 1988, PSI won U.S. Department of Commerce recognition as Virginia's Exporter of the Year. 